\title{
Türkiye'de İşlenmiş Tarım Ürünleri Dış Ticaretinde Dâhilde İşleme Rejiminin Etkilerinin Trend Analizi Yöntemiyle İncelenmesi
}

\author{
Oğuz PARLAKAY ${ }^{1 *}$, Sinan DURU ${ }^{2}$ \\ ${ }^{1}$ Mustafa Kemal Üniversitesi Ziraat Fakültesi Tarım Ekonomisi Bölümü, Hatay \\ ${ }^{2}$ TC Ekonomi Bakanlığı Ürün Denetmenleri Mersin Grup Başkanlığı, Mersin \\ *Sorumlu yazar: oparlakay@mku.edu.tr
}

\begin{abstract}
Öz
İhracatı artırmak için geliştirilen politikaların uygulanmasında kullanılan araçlardan biri de Dâhilde İşleme Rejimi (DiR) teşvik sistemidir. DiR sistemi, temelinde ithal girdi kullanılan işlem görmüş ürün ihracatını artırmaya yönelik bir sistemidir. Türkiye'nin Dünya Ticaret Örgütü’ne üye olması ve Avrupa Birliği (AB) ile Gümrük Birliği anlaşması yapması ihracatı teşvik mevzuatının $A B$ mevzuatıyla uyumlu olması zorunluluğunu ortaya çıkarmıştır. Bu bağlamda önceden uygulanan nakit teşvikler kaldırılarak faaliyetlerin desteklendiği DiR sisteminin uygulanmasına başlanmış ve Türkiye'de ihracatın artırılması için uygulanan en önemli teşvik sistemi olmuştur. Bu çalışma ile DíR teşvik sistemi uygulamasının başladığı 1996 yııından bu yana Türkiye'nin işlenmiş tarım ürünleri dış ticaretinin gelişimi incelenerek Trend Analizi yöntemiyle yakın gelecekteki seyri tahmin edilmiştir. Çalışmanın ana materyalini Ekonomi Bakanlığı, Türkiye İstatistik Kurumu (TÜiK) ve Dünya Gıda ve Tarım Örgütü'nden (FAO) alınan veriler oluşturmaktadır. Bununla birlikte konu ile ilgili yapılmış çalışmalardan faydalanılmıştır. Yöntem olarak zaman serileri analiz yöntemlerinden Trend analizi kullanılmıştır. Çalışma, işlenmiş tarım ürünlerinde DíR teşvik sisteminin uygulamasının ülke ihracatına dolayısıyla milli gelire katkılarını göstermesi açısından önemlidir. DiR sisteminin devam ettirilmesi işletmelerin atıl kapasitesini değerlendirebilmeleri ve işletmelere daha fazla kazanç sağlamaları için fırsat oluşturacaktır.
\end{abstract}

Anahtar Kelimeler: Dış ticaret, Dâhilde işleme rejimi, Hammadde, Trend analizi

\section{Investigation of the Effects of Inward Processing Regime in Foreign Trade of Processed Agricultural Products by Trend Analysis Method in Turkey}

\begin{abstract}
One of the political tools to boost export is Inward Processing Regime (IPR) promotion system. IPR is a system to improve export of processed goods made by imported input. It is because Turkey is a member of World Trade Organization and customs unions agreement between Turkey and EU, it is essential to synchronize Turkey's export promotion regulations with EU. In this study, foreign trade development of Turkey's processed agricultural products was examined since 1996 when the time IPR promotion system has started and near future progress was predicted by using of Trend Analysis. The main data of the study was gathered from Ministry of Economy, Turkish Statistical Institute (TÜiK, its Turkish acronym) and Food and Agriculture Organization (FAO), and also previous studies about the topic were used. As method, Trend Analysis which is one of the serial analysis methods was used. The study is important in terms of presenting IPR's contribution to country's foreign trade of agricultural products and national income as well. Maintaining IPR will provide an opportunity to utilize spare capacity, and increasing agricultural enterprises' income.
\end{abstract}

Keywords: Foreign trade, Inward processing regime, Raw material, Trend analysis. 


\section{Giriş}

Ihracata dayalı büyüme modelinin benimsendiği dönemden itibaren ihracatın geliştirilmesi ve artırılması yönünde yoğun çalışmalar yapılmış, özellikle teşvik uygulamaları ile ihracat yapılan sektörlerin uluslararası ekonomide rekabet edebilmesi desteklenmeye çalışılmıştır. $\mathrm{Bu}$ yönde Türkiye'de ihracat sektörlerinin asıl ihtiyacı olan ucuz ve kaliteli girdi teminini kolaylaştırmak amacıyla Dâhilde i̇şleme Rejimi indas edilmiş ve 1996 yılında uygulamaya konulmuştur (Bıyıkçı, 2010). Dâhilde İşleme Rejimi teşvik sistemi 1996 yılında Avrupa Birliği ile Türkiye arasında oluşturulan Gümrük Birliği anlaşması çerçevesinde yürürlüğe girmiştir (Namlı, 2007). Gümrük Birliği, Türkiye ile Avrupa Birliği arasındaki sanayi malları ve işlenmiş tarım ürünlerini kapsamaktadır (Yılmaz, 2008).

Dâhilde işleme hammaddenin, parçanın veya ürünün vergiden muaf tutarak ithal edilmesi ve oluşan nihai ürünün ihraç edilmesidir (Anonymous, 2012). DiR'den firmalar dış ticaret sermaye şirketleri, sektörel dış ticaret şirketleri, imalatçıihracatçılar ve sermayenin en az $\% 51^{\prime} i$ imalatçıya ait olması kaydıyla yaralanmaktadır (Anonim, 2012b).

Ülkemizde DiR'i yürütme yetkisi 4458 sayılı Gümrük Kanunu ile Gümrük ve Ticaret Bakanlığı'na devredilmiştir. Ancak DiR kapsamında firmalara Dâhilde İşleme İzin Belgesi (DiiB) Ekonomi Bakanlığı tarafından düzenlenmektedir. Bakanlık tarafından düzenlenen, re'sen kapatılan ve iptal edilen ve firma talebiyle iptal edilen Diï'ler bir sonraki ay içersinde resmi gazetede yayınlanmaktadır (Duru, 2014). Dâhilde Işleme İzin Belgesi'nde firma bilgileri, döviz kullanım oranı (CIF ithalat/FOB ihracat), ihraç ve ithal edilecek ürünler, öngörülen ithalat ve ihracat değerleri, bağlı bulunduğu sektör, belge süresi (ihracat/ithalat süreleri) ve belge kapsamında yerine getirilmesi gereken özel şartlar yer almaktadır. Bu çalışma ile Türkiye'de DiR teşvik sisteminin uygulandığı işlenmiş tarım ürünleri dış ticaretinin incelenmesi amaçlanmıştır.

\section{Materyal ve Metot}

Materyal

Bu çalışmanın ana materyalini, Ekonomi Bakanlığı, Türkiye İstatistik Kurumu (TÜiK) ve Dünya Gıda ve Tarım Örgütünden (FAO) alınan veriler oluşturmaktadır. Konuyla ilgili daha önceden yayınlanmış, raporlar, tezler, makaleler, Ekonomi Bakanlığı tarafından yayınlanan tebliğ ve genelgeler ile TÜik'den alınan istatistiki veriler derlenerek analiz edilmiştir.

\section{Metot}

Verilerin analizinde 1996-2014 dönemi dış ticaret verilerinin eğilimini belirlemek için zaman serisi analizi yöntemlerinden Trend analizi kullanılmıştır. Ayrıca veriler ve elde edilen tahmin değerleri çizelgeler ve grafiklerle özetlenerek yorumlanmıştır. Trend analizine göre; işlenmiş tarım ürünleri için ithalat ve ihracat değerlerinin yıllara göre gösterdiği eğilim "En Küçük Kareler Yöntemi” ile hesaplanmıştır. Bu yönteme göre eğilimi tahmin edebilmek için $Y=a+b X$ denklemi kullanıımıştır. Denklemdeki a değeri; $a=\bar{Y}-b \bar{X}$

b değeri ise; $\quad b=\frac{\sum X Y-n \bar{X} \bar{Y}}{\sum X^{2}-n \bar{X}^{2}}$ eşitlikleri kullanılarak elde edilmiştir (Güneş ve Arıkan, 1998). 


\section{Araştırma Bulguları ve Tartışma}

Dâhilde işleme Rejimine Konu Olan İşlenmiş Tarım Ürünleri

Dâhilde İşleme Rejimi uygulama usul ve esaslarını belirlemek amacıyla Ekonomi Bakanlığı (Dış Ticaret Müsteşarlığı) tarafından 20.12.2006 tarihli ve 26382 sayılı Resmi Gazete'de "ihracat: 2006/12 sayılı Dâhilde İşleme Rejimi Tebliği" hükümleri yayınlanmıştır. İşlenmiş tarım ürünleri 2006/12 sayılı Dâhilde İşleme Rejimi Tebliği'nde "ithalat Rejim Kararının III. listesinde yer alan ve bünyesinde temel tarım ürünlerini (hububat, şeker ve süt) bulunduran ürünler" şeklinde geçmektedir (Anonim, 2006).

Ancak; Tarım ürünleri kapsamının çok geniş olması sebebiyle 12 Aralık 2011 tarihinde 2011/1 sayılı "Tarım Ürünlerine İlişkin Dâhilde İşleme Rejimi Genelgesi" düzenlenmiştir. Bu genelge ithali vergiye tabi tarım ürünleri ile DíR kapsamında yapılacak yurtiçi alımlara (T.C. Şeker Kurumunca tespit edilen şeker fabrikalarından şeker alımı ve Toprak Mahsulleri Ofisi'nden buğday alımı) ilişkin uygulanacak dâhilde işleme tedbirlerini kapsamaktadır (Anonim, 2011).

Tarım Ürünlerine Illişkin 2011/1 sayılı DiR genelgesine göre Gümrük Tarife Cetvelinin 124 üncü fasıllarında yer alan ve DiR kapsamında olan tarım ürünlerinin ihracatına ilişkin düzenlenecek DiiB süreleri belirlenmiştir. Tarım ürünlerine ilişkin DiiB süresi 6-24 ay arasında değişmektedir. DíR kapsamında yapılacak olan hammadde ithalatına yurt içi üreticiyi korumak adına bazı dönemlerde (ürünün hasat döneminde) yasaklamalar getirilmiştir. Örneğin; mercimek için 1 Mayıs ile 30 Eylül, ham ayçiçeği yağı ve tohumu için 1 Ağustos ile 31 Ekim tarihleri arasında ithalatına izin verilmemektedir. Ancak, ihracat taahhüdüne konu olan eşyanın ihracatı tamamen gerçekleşmesi ve uluslararası devlet ve kuruluşların açmış oldukları ihaleler için bu dönemde ithalata izin verilebilir (Anonim, 2011).

Dâhilde işleme Rejimine Konu Olan İşlenmiş Tarım Ürünleri Dış Ticareti

DíR kapsamında ithalatına izin verilen başlıca tarım ürünleri bitkisel yağ, hububat, ceviz, tütün mamulleri, hayvansal yemlerdir. DiR kapsamında ithalatına izin verilmeyen ürünler ise dünya üretiminde söz sahibi olduğumuz zeytin ve zeytinyağı, meyve ve sebze (yaş ve konserve), çay, kurutulmuş ürünler (kuru kayısı, fındık ve incir) olarak sayılabilir. Bu ürünlerin ithalatına DíR kapsamında izin verilmez iken belli şartlarda (mamul ürün olarak kullanılması gibi) yurt içi alım şeklinde izin verilmektedir (Anonim, 2011). Ayrıca DiR kapsamında büyükbaş ve küçükbaş hayvan ithalatına izin verilmemektedir. Bunun nedeni büyük ve küçükbaş hayvancilık sektörünü kontrol altına almak dış etkilerden korumak ve kendi iç dinamikleriyle hareket eden bir sektör haline getirmektir (Bıyıkçı, 2010). Incelenen dönemde Türkiye'de toplam DíR kapsamında ve işlenmiş tarım ürünleri kapsamında gerçekleşen ithalat ve ihracat verileri çizelge ve grafiklerle açıklanmıştır.

ithalat

Incelenen döneme ait toplam ithalat, DiR kapsamında ithalat ve işlenmiş tarım ürünleri ithalat değerleri ve Trend analiziyle tahmin edilen değerler Çizelge 1'de ve Şekil 1'de verilmiştir. 
Çizelge 1. Türkiye'de toplam ve DíR kapsamında ithalat değerleri (Milyon \$)

Table 1. Import values in total and IPR in Turkey (Millions \$)

\begin{tabular}{|c|c|c|c|c|c|c|}
\hline \multirow[t]{2}{*}{$\begin{array}{l}\text { Dönem/ } \\
\text { Period }\end{array}$} & \multicolumn{2}{|c|}{$\begin{array}{l}\text { Toplam İthalat / Total } \\
\text { Import }\end{array}$} & \multicolumn{2}{|c|}{$\begin{array}{l}\text { DiR Kapsamında İthalat / } \\
\text { IPR Import }\end{array}$} & \multicolumn{2}{|c|}{$\begin{array}{l}\text { İşl. Tarım Ürünleri İth. / } \\
\text { Processed Agricultural } \\
\text { Products Import }\end{array}$} \\
\hline & $\begin{array}{l}\text { Gerçekleşen } \\
\text { / Realized }\end{array}$ & $\begin{array}{l}\text { Tahmin* / } \\
\text { Estimate * }\end{array}$ & $\begin{array}{c}\text { Gerçekleşen } \\
\text { / Realized }\end{array}$ & $\begin{array}{l}\text { Tahmin* / } \\
\text { Estimate * }\end{array}$ & $\begin{array}{c}\text { Gerçekleşen / } \\
\text { Realized }\end{array}$ & $\begin{array}{l}\text { Tahmin* / } \\
\text { Estimate * }\end{array}$ \\
\hline 1996 & 43.627 & 5.823 & 5.050 & 4.746 & 4.028 & 1.007 \\
\hline 1997 & 48.559 & 19.323 & 8.282 & 6.441 & 4.058 & 1.634 \\
\hline 1998 & 45.921 & 32.824 & 7.854 & 8.136 & 3.434 & 2.261 \\
\hline 1999 & 40.671 & 46.324 & 6.846 & 9.832 & 2.575 & 2.889 \\
\hline 2000 & 54.503 & 59.824 & 8.103 & 11.527 & 3.131 & 3.516 \\
\hline 2001 & 41.399 & 73.325 & 9.212 & 13.222 & 2.336 & 4.144 \\
\hline 2002 & 51.554 & 86.825 & 11.788 & 14.918 & 2.954 & 4.771 \\
\hline 2003 & 69.340 & 100.325 & 17.055 & 16.613 & 4.020 & 5.398 \\
\hline 2004 & 97.540 & 113.826 & 22.422 & 18.308 & 4.440 & 6.026 \\
\hline 2005 & 116.774 & 127.326 & 24.615 & 20.004 & 4.680 & 6.653 \\
\hline 2006 & 139.576 & 140.827 & 24.526 & 21.699 & 5.120 & 7.281 \\
\hline 2007 & 170.073 & 154.327 & 30.174 & 23.394 & 7.045 & 7.908 \\
\hline 2008 & 201.964 & 167.827 & 30.780 & 25.089 & 9.956 & 8.535 \\
\hline 2009 & 140.928 & 181.328 & 20.482 & 26.785 & 7.387 & 9.163 \\
\hline 2010 & 185.544 & 194.828 & 25.140 & 28.480 & 9.724 & 9.790 \\
\hline 2011 & 240.842 & 208.328 & 29.958 & 30.175 & 13.623 & 10.417 \\
\hline 2012 & 236.545 & 221.829 & 34.202 & 31.871 & 12.425 & 11.045 \\
\hline 2013 & 251.661 & 235.329 & 32.872 & 33.566 & 13.056 & 11.672 \\
\hline 2014 & 242.177 & 248.830 & 30.707 & 35.261 & 12.417 & 12.300 \\
\hline 2015 & & 262.330 & & 36.957 & & 12.927 \\
\hline 2016 & & 275.830 & & 38.652 & & 13.554 \\
\hline 2017 & & 289.331 & & 40.347 & & 14.182 \\
\hline 2020 & & 329.832 & & 45.433 & & 16.064 \\
\hline
\end{tabular}

Kaynak: Anonim, $2014 . \quad$ /Source: Anonymous, 2014

*Tahmin değerleri Trend analizi yöntemiyle elde edilen denklemler kullanılarak hesaplanmıştır.

*Forecast values are calculated using equations obtained by Trend analysis method.

TÜik verilerine göre 2014 yılında Türkiye yaklaşık 242 milyar $\$$ değerinde ürün ithal etmiştir. Bu değerin yaklaşık 31 milyar \$'ı DíR kapsamında gerçekleştirilmiştir. İthal edilen ürünlerin yaklaşık 12.5 milyar \$'lık kısmı işlenmiş tarım ürünlerinden oluşmaktadır (Anonim, 2014).

Türkiye'de DíR kapsamında en fazla ithalatı gerçekleştirilen işlenmiş tarım ürünleri hububattan buğday ve mısır; baklagillerden mercimek, soya fasulyesi; sert kabuklu meyvelerden kabuklu ceviz ve iç badem; bitkisel yağ hammaddelerinden ham ayçiçeği yağı, soya yağı ve mısıryağı sayılabilir.

Incelenen dönemde Türkiye'nin toplam ithalat değeri 4.5 kat, DíR kapsamında hammaddesi ithal edilerek ihraç edilen ürünlerin ithalat değeri $6.5 \mathrm{~kat}$, işlenmiş tarım ürünleri ithalat değeri yaklaşık 2 kat artış göstermiştir (Çizelge 1). Analiz sonucuna göre ithalat değerlerinin gelecek yıllarda artış eğilimi göstereceği tahmin edilmektedir. 
Dönemin işlenmiş tarım ürünleri ithalat değeri Trend denklemi;

$\mathrm{Y}=379.16+627.39 \times(\mathrm{X}=1 ; 1996)$ olarak hesaplanmıştır (Şekil 1).

Elde edilen Trend Denkleminden gerçekleşmesi beklenen işlenmiş tarım ürünleri ithalat değeri 2015 yılı için yaklaşık
13.5 milyar \$, 2020 yılı için yaklaşık 16 milyar \$ olarak tahmin edilmektedir. Trend doğrusunun eğimi pozitiftir. Bu dönemde genel eğilim olarak işlenmiş tarım ürünleri ithalat değeri yılda 627.39 milyon \$ artış göstermiştir. Konjonktür 8 yıl genel trendin üstünde, 10 yıl altında seyretmiştir.

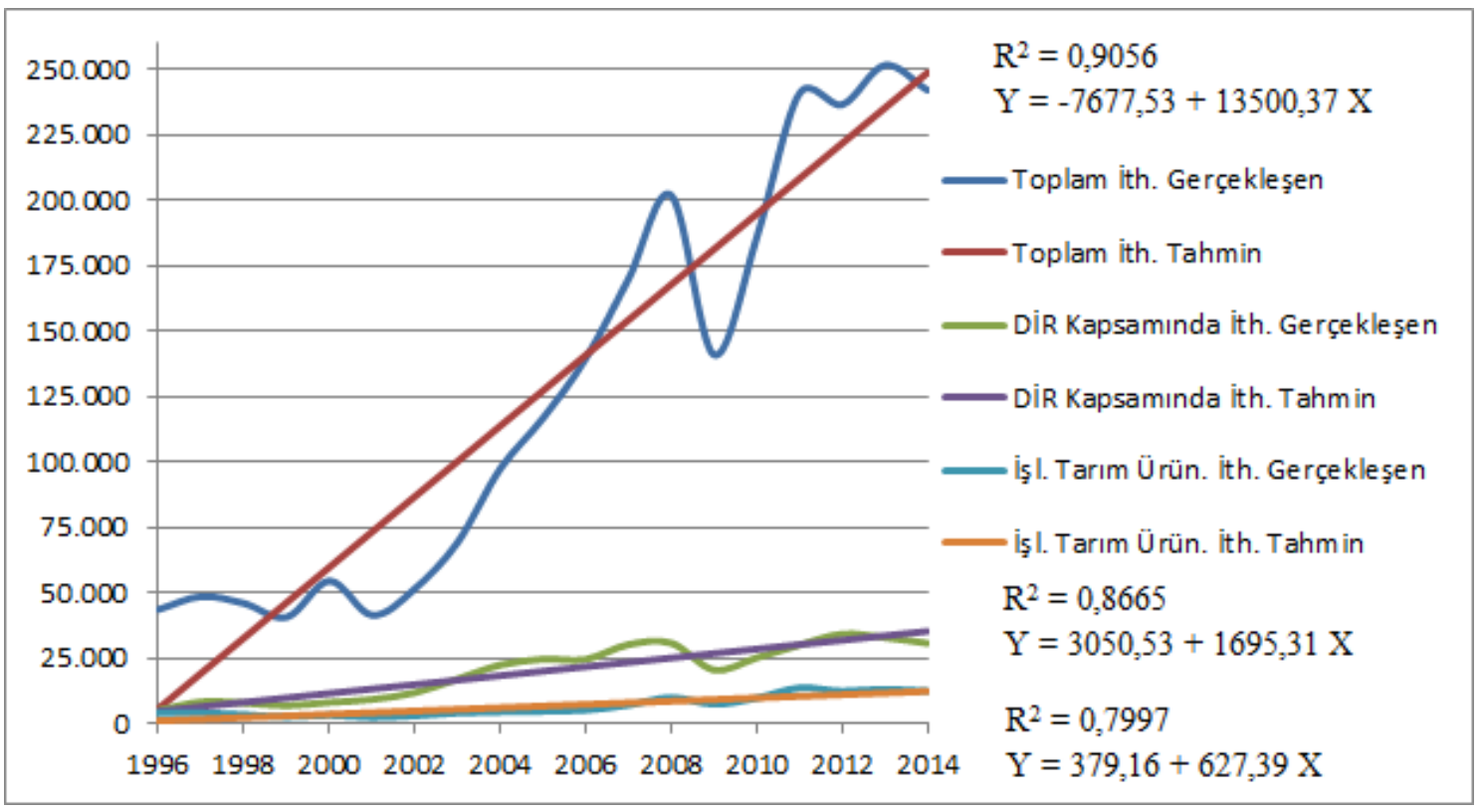

Şekil 1. Türkiye'de toplam ve DiR kapsamında ithalat değerleri ve trend analizi yöntemiyle hesaplanan tahmini değerler (Milyon \$)

Figure 1. Imported values in total and IPR in Turkey and estimated values calculated by trend analysis method (Millions \$).

Toplam ithalat değerlerinin 1999, 2001 ve 2009 yılları dışında artan bir grafik çizdiği görülmektedir. Incelenen dönem boyunca tarım ürünleri ithalatında buğday önemli yer tutarak, 2015 yılı dışında liderliği elinde bulundurmuştur. İşlenmiş tarım ürünleri ithalatında 1996-2007 yılları arasında değişim küçük dalgalanmalar halinde gerçekleşmiş olup, 2008'de önemli artışlar gerçekleşmiştir. 2011'den itibaren dönem sonuna kadar artışlar devam etmiştir. DiR'in uygulanmaya başlandığı 1996 yılından itibaren bazı işlenmiş tarım ürünlerinin ithalat değerleri Çizelge 2'de verilmiştir. Bu verilere göre DiR kapsamında değer olarak en fazla ithalatı yapılan ürünler buğday, soya fasulyesi ve yemeklik ayçiçeği yağı olmuştur. Dokuzuncu kalkınma planına göre ülkemizde gıda sanayinde ithalat değerinin en yüksek ürünlerin bitkisel yağ ve tahıl nişasta ürünlerinin olması bu verileri destekler niteliktedir (Anonim, 2007). 
Çizelge 2. Türkiye'de bazı tarım ürünleri ithalat değerleri (Milyon \$)

Table 2. Import values of some agricultural products in Turkey (Million \$)

\begin{tabular}{|c|c|c|c|c|c|c|c|c|c|}
\hline $\begin{array}{l}\text { Yıllar } \\
\text { /Years }\end{array}$ & $\begin{array}{l}\text { Buğday } \\
\text { / } \\
\text { Wheat }\end{array}$ & $\begin{array}{l}\text { Mercimek } \\
\text { / Lentil }\end{array}$ & $\begin{array}{c}\text { Misır } \\
/ \\
\text { Maize }\end{array}$ & $\begin{array}{c}\text { Soya } \\
\text { Fasulyesi } \\
/ \\
\text { Soybean }\end{array}$ & $\begin{array}{l}\text { Y.Ayçiçeği } \\
\text { yağı -ham } \\
\text { / Edible } \\
\text { sunflower } \\
\text { oil-crude }\end{array}$ & $\begin{array}{l}\text { Y.Mısır } \\
\text { yağı- } \\
\text { ham / } \\
\text { Edible } \\
\text { maize } \\
\text { oil - } \\
\text { crude }\end{array}$ & $\begin{array}{c}\text { Kabuklu } \\
\text { Ceviz / } \\
\text { Shelled } \\
\text { walnut }\end{array}$ & $\begin{array}{c}\text { İç } \\
\text { Badem } \\
\text { /Inner } \\
\text { almond }\end{array}$ & $\begin{array}{c}\text { Diğer } \\
/ \\
\text { Other }\end{array}$ \\
\hline 1996 & 485 & 5 & 176 & 46 & 113 & 55 & 0.4 & 0.4 & 68 \\
\hline 1997 & 457 & 39 & 130 & 81 & 129 & 57 & 0.3 & 0.6 & 96 \\
\hline 1998 & 232 & 36 & 98 & 78 & 103 & 47 & 0.5 & 0.6 & 110 \\
\hline 1999 & 186 & 29 & 98 & 74 & 73 & 54 & 0.6 & 0.6 & 96 \\
\hline 2000 & 126 & 59 & 147 & 83 & 40 & 46 & 2 & 0.5 & 79 \\
\hline 2001 & 50 & 38 & 66 & 67 & 63 & 39 & 0.4 & 0.8 & 61 \\
\hline 2002 & 148 & 8 & 134 & 140 & 52 & 62 & 1.7 & 2.5 & 79 \\
\hline 2003 & 276 & 8 & 276 & 219 & 54 & 69 & 1.8 & 2 & 79 \\
\hline 2004 & 222 & 3 & 190 & 227 & 51 & 67 & 4.6 & 3.6 & 50 \\
\hline 2005 & 25 & 29 & 47 & 329 & 135 & 89 & 3.2 & 4.4 & 111 \\
\hline 2006 & 53 & 31 & 13 & 265 & 237 & 89 & 9.1 & 7.9 & 126 \\
\hline 2007 & 570 & 18 & 269 & 410 & 138 & 98 & 15.4 & 7.1 & 37 \\
\hline 2008 & 1.483 & 244 & 382 & 648 & 647 & 139 & 28.2 & 20.9 & 41 \\
\hline 2009 & 902 & 134 & 135 & 429 & 468 & 71 & 42.2 & 24.1 & 10 \\
\hline 2010 & 655 & 194 & 124 & 742 & 272 & 56 & 50.5 & 26.9 & 8 \\
\hline 2011 & 1.623 & 206 & 136 & 687 & 629 & 57 & 79.9 & 32 & 6 \\
\hline 2012 & 1.126 & 106 & 247 & 684 & 987 & 43 & 99.7 & 51.5 & 1.1 \\
\hline 2013 & 1.289 & 132 & 474 & 642 & 908 & 41 & 90.6 & 40.5 & 7.1 \\
\hline 2014 & 1.546 & 202 & 352 & 1.119 & 1.177 & 24 & 102.7 & 41.8 & 8.4 \\
\hline $2015^{*}$ & 1.103 & 237 & 348 & 968 & 1.075 & 27 & 115.4 & 53.7 & 2.5 \\
\hline
\end{tabular}

İncelenen dönemde ithalatı yapılan ürünlerin hammaddelerinin (yemeklik bitkisel yağlar hariç) dönem başından sonuna hepsinde artış gerçekleşmiştir. Bu artış buğdayda 2.2 kat, mercimekte 39.4 kat, mısırda 1 kat, soya fasulyesinde 23.3 kat, yemeklik ayçiçeği yağında, 9.4 kat, kabuklu cevizde 255.8 kat, iç bademde 103.5 kat olarak gerçekleşmiştir.

\section{ihracat}

DiR'in uygulanmaya başlandığı 1996 yllından itibaren toplam ihracat, DiR kapsamında ihracat ve işlenmiş tarım ürünleri ihracat değerleri ve Trend analiziyle tahmin edilen değerler Çizelge 3 'te ve Şekil 2'de verilmiştir. Bu verilere göre dönem başında 23 milyar \$ olan toplam ihracat değeri 5.8 kat artarak yaklaşık 158 milyar \$' a ulaşmıştır. Bu dönemde DiR kapsamında hammaddesi ithal edilerek ihraç edilen ürünlerin değeri dönem başından dönem sonuna 6.5 kattan fazla artarak yaklaşık 67 milyar \$ olarak gerçekleşmiştir. İncelenen dönemde işlenmiş tarım ürünleri ihracat değeri yaklaşık 3 kat artarak yaklaşık 17.8 milyar \$ olarak gerçekleşmiştir. Dönem başında işlenmiş tarım ürünleri ihracatının toplam ihracat içindeki payı \%20 iken 2014 yılında toplam ihracattaki payı \%11.26 olarak gerçekleşmiştir (Çizelge 3). 
Çizelge 3. Yıllara göre toplam ve DíR kapsamında yapılan ihracat değerleri (Milyon \$)

Table 3. Export values in total and IPR by years (Million \$)

\begin{tabular}{|c|c|c|c|c|c|c|}
\hline \multirow[t]{2}{*}{$\begin{array}{l}\text { Yıllar / } \\
\text { Years }\end{array}$} & \multicolumn{2}{|c|}{ Toplam İhracat / Total Export } & \multicolumn{2}{|c|}{ DiR ihracat / IPR Export } & \multicolumn{2}{|c|}{$\begin{array}{c}\text { İşl. Tarım Ürünleri îhr. / } \\
\text { Processed Agricultural Products } \\
\text { Export }\end{array}$} \\
\hline & $\begin{array}{c}\text { Gerçekleşen / } \\
\text { Realized }\end{array}$ & $\begin{array}{l}\text { Tahmin* / } \\
\text { Estimate * }\end{array}$ & $\begin{array}{c}\text { Gerçekleşen / } \\
\text { Realized }\end{array}$ & $\begin{array}{l}\text { Tahmin* / } \\
\text { Estimate * }\end{array}$ & $\begin{array}{c}\text { Gerçekleşen / } \\
\text { Realized }\end{array}$ & $\begin{array}{l}\text { Tahmin* / } \\
\text { Estimate * }\end{array}$ \\
\hline 1996 & 23.225 & 2.836 & 8.922 & 4.071 & 4.629 & 1.564 \\
\hline 1997 & 26.261 & 11.409 & 14.713 & 7.715 & 5.116 & 2.335 \\
\hline 1998 & 26.973 & 19.981 & 13.747 & 11.359 & 4.725 & 3.106 \\
\hline 1999 & 26.588 & 28.553 & 12.224 & 15.002 & 4.127 & 3.877 \\
\hline 2000 & 27.775 & 37.125 & 14.017 & 18.646 & 3.512 & 4.648 \\
\hline 2001 & 31.334 & 45.698 & 15.577 & 22.289 & 4.014 & 5.420 \\
\hline 2002 & 36.059 & 54.270 & 19.034 & 25.933 & 3.676 & 6.191 \\
\hline 2003 & 47.253 & 62.842 & 26.797 & 29.577 & 4.835 & 6.962 \\
\hline 2004 & 63.167 & 71.415 & 34.044 & 33.220 & 5.978 & 7.733 \\
\hline 2005 & 73.476 & 79.987 & 37.741 & 36.864 & 7.725 & 8.504 \\
\hline 2006 & 85.535 & 88.559 & 36.649 & 40.508 & 7.937 & 9.275 \\
\hline 2007 & 107.272 & 97.131 & 45.853 & 44.151 & 9.032 & 10.046 \\
\hline 2008 & 132.027 & 105.704 & 62.796 & 47.795 & 10.640 & 10.817 \\
\hline 2009 & 102.143 & 114.276 & 45.528 & 51.438 & 10.457 & 11.588 \\
\hline 2010 & 113.883 & 122.848 & 52.441 & 55.082 & 11.778 & 12.360 \\
\hline 2011 & 134.906 & 131.421 & 62.790 & 58.726 & 14.214 & 13.131 \\
\hline 2012 & 152.462 & 139.993 & 63.680 & 62.369 & 14.872 & 13.902 \\
\hline 2013 & 151.802 & 148.565 & 66.737 & 66.013 & 16.550 & 14.673 \\
\hline 2014 & 157.610 & 157.138 & 67.124 & 69.656 & 17.759 & 15.444 \\
\hline 2015 & & 165.710 & & 73.300 & & 16.215 \\
\hline 2016 & & 174.282 & & 76.944 & & 16.986 \\
\hline 2017 & & 182.854 & & 80.587 & & 17.757 \\
\hline 2020 & & 208.571 & & 91.518 & & 20.071 \\
\hline
\end{tabular}

Kaynak: TÜiK ve Resmi Gazete, Source: TSI and TR Official Gazette

*Tahmin değerleri trend analizi yöntemiyle elde edilen denklemler kullanılarak hesaplanmıştır.

* Forecast values are calculated using equations obtained by trend analysis method.

Analiz sonucunda ihracat değerlerinin gelecek yıllarda artış eğilimi göstermesi beklenmektedir. Dönemin işlenmiş tarım ürünleri ihracat değeri Trend denklemi $\mathrm{Y}=792.77+771.12 \mathrm{X} \quad(\mathrm{X}=1 ; 1996)$ olarak hesaplanmıştır (Şekil 2). 


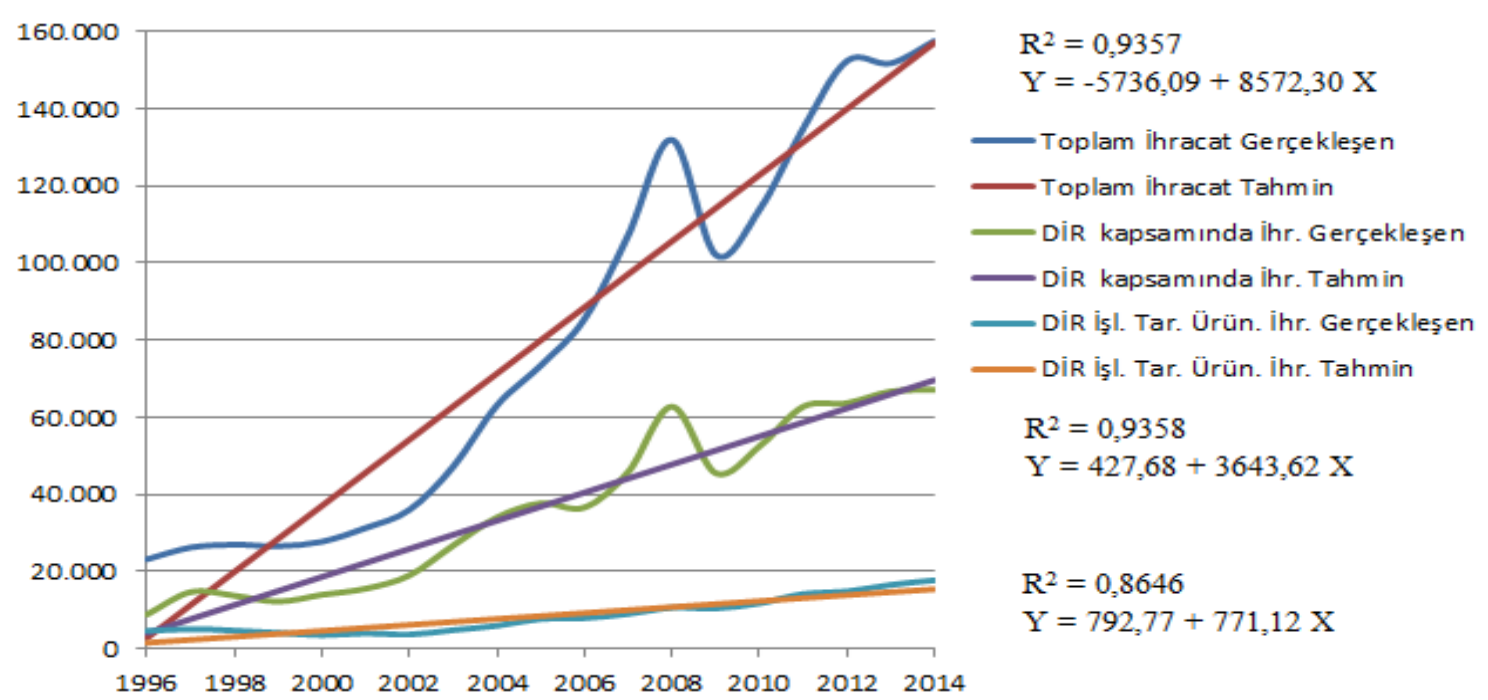

Şekil 2. Türkiye'de toplam ve DíR kapsamında ihracat değerleri ve trend analizi yöntemiyle hesaplanan tahmini değerler (Milyon \$)

Figure 2. Exported values in total and IPR in Turkey and estimated values calculated by trend analysis method (Millions \$).

Elde edilen Trend Denkleminden gerçekleşmesi beklenen işlenmiş tarım ürünleri ihracat değeri 2015 yılı için yaklaşık 16.2 milyar \$, 2020 yılı için 20 milyar \$'ın üzerinde tahmin edilmektedir. Trend doğrusunun eğimi pozitiftir. Bu dönemde genel eğilim olarak işlenmiş tarım ürünleri ihracat değeri yılda 8572.30 milyon \$ artış göstermiştir. Konjonktür 8 yıl genel trendin üstünde, 10 yıl altında seyretmiştir.

Türkiye'de DíR kapsamında en fazla ihracatı gerçekleştirilen işlenmiş tarım ürünleri; buğday unu, mercimek, iç ceviz, iç badem, yemeklik ayçiçeği yağı, yemeklik soya yağı ve yemeklik mısıryağıdır. Bu ürünlere ilişkin 1996-2014 yılları arasında gerçekleşen ihracat değerleri Çizelge 4'de verilmiştir. Dönem başından dönem sonuna buğday ununda 4.5 kat, mercimekte 0.7 kat, iç cevizde 48.3 kat, iç bademde 57.9 kat, yemeklik ayçiçeği yağında 46.5 kat, yemeklik soya yağında 30 kat olarak gerçekleşmiştir. inracat gelirinin en fazla olduğu ürünler buğday unu ve yemeklik ayçiçeği yağıdır.
DiR kapsamında ithalatı yapılan tarım ürünlerinin işlenmesi sonucu ayrıca yan ürün (ikincil işlem görmüş ürün) oluşmaktadır. Tarım ürünlerine ilişkin 2011/1 sayılı DíR genelgesinde buğday, ayçiçeği tohumu, soya fasulyesi, çeltik ve kargo pirinci için ikincil işlem görmüş ürünün oluşumu için azami oranlar belirtilmiştir. Üretim faaliyeti sonucu oluşan 2.işlem görmüş ürünün gümrük vergisi ödenerek (millileştirme yapılarak) yurt içinde kullanımına izin verilmektedir. 2011/1 sayılı DiR genelgesinde ikincil işlem görmüş ürünlerden bulgur, makarna ve un kepekleri için azami beyan fiyat seviyeleri belirlenmiştir (Anonim, 2011).

DíR kapsamında ithal edilen buğday işlenerek buğday unu olarak, mısır işlenerek mısıryağı olarak, ceviz ve badem kabuklarından ayıklanarak iç ceviz ve iç badem olarak ihracatı yapılmaktadır. İthal edilen ürünlerin işlenmesiyle elde edilen ana ürünün yanında yan ürün de elde edilmektedir. Bu yan ürünler gümrük vergisi ödenerek yurt içinde kullanıldığından ithalat 
değeri ihracat değerlerinden yüksek çıkmaktadır.

Çizelge 4. Türkiye'de işlenmiş tarım ürünleri ihracat değerleri (Milyon \$)

Table 4. Export value of agricultural products processed in Turkey (\$ Million)

\begin{tabular}{|c|c|c|c|c|c|c|c|}
\hline $\begin{array}{l}\text { Yillar } \\
\text { /Years }\end{array}$ & $\begin{array}{l}\text { Buğday } \\
\text { Unu / } \\
\text { Wheat } \\
\text { Flour }\end{array}$ & $\begin{array}{c}\text { Mercimek } \\
\text { / Lentil }\end{array}$ & $\begin{array}{l}\text { İç Ceviz / } \\
\text { Inner } \\
\text { walnut }\end{array}$ & $\begin{array}{l}\text { İç } \\
\text { Badem / } \\
\text { Inner } \\
\text { almond }\end{array}$ & $\begin{array}{l}\text { Y.Ayçiçeği } \\
\text { Yağı / } \\
\text { Edible } \\
\text { sunflower } \\
\text { oil }\end{array}$ & $\begin{array}{l}\text { Y.Soya Yağı / } \\
\text { Edible } \\
\text { soybean oil }\end{array}$ & $\begin{array}{l}\text { Y.Mısır Yağı } \\
\text { / Edible } \\
\text { maize oil }\end{array}$ \\
\hline 1996 & 175 & 112 & 1.3 & 1,2 & 17 & 0.1 & 31.2 \\
\hline 1997 & 263 & 79 & 1.4 & 1,5 & 55 & 0.3 & 18.8 \\
\hline 1998 & 99 & 88 & 0.8 & 0,2 & 58 & 0.6 & 2.2 \\
\hline 1999 & 48 & 57 & 0.7 & 0,7 & 26 & 1.2 & 6.4 \\
\hline 2000 & 70 & 58 & 1.2 & 0,8 & 20.5 & 0.7 & 8.5 \\
\hline 2001 & 34 & 85 & 1.4 & 1,3 & 12 & 0.6 & 8.4 \\
\hline 2002 & 45 & 46 & 0.4 & 0,6 & 8.2 & 3.2 & 6.9 \\
\hline 2003 & 115 & 88 & 0.9 & 1,4 & 22.5 & 12.0 & 8.6 \\
\hline 2004 & 203 & 85 & 1.3 & 2,5 & 15.7 & 3.2 & 14.7 \\
\hline 2005 & 432 & 71 & 1.2 & 7,8 & 35.8 & 2.3 & 26.0 \\
\hline 2006 & 224 & 125 & 1.4 & 4,4 & 170.4 & 1.8 & 24.4 \\
\hline 2007 & 321 & 93 & 4.3 & 13,5 & 89.6 & 7.1 & 6.6 \\
\hline 2008 & 641 & 101 & 13.3 & 28,9 & 378.4 & 8.7 & 7.0 \\
\hline 2009 & 597 & 175 & 10.5 & 38,6 & 231.4 & 3.3 & 17.6 \\
\hline 2010 & 621 & 217 & 23.5 & 36,5 & 167.6 & 3.9 & 24.2 \\
\hline 2011 & 934 & 201 & 36.4 & 47,6 & 672 & 8.1 & 48 \\
\hline 2012 & 870 & 161 & 59.8 & 65,2 & 873.7 & 4.6 & 44.5 \\
\hline 2013 & 962 & 168 & 46.8 & 91,6 & 800.2 & 13.1 & 48.9 \\
\hline 2014 & 954 & 193 & 64.1 & 70,7 & 807.2 & 3.1 & 29.5 \\
\hline
\end{tabular}

Kaynak: TÜiK, 2015, Source: TSI, 2015

\section{Sonuçlar}

Yapılan çalışma sonucunda elde edilen bulgulardan çıkarılabilecek sonuçlar özetlenerek aşağıda sunulmuştur.

Türkiye'de DíR kapsamında en fazla ithalatı gerçekleştirilen işlenmiş tarım ürünleri buğday, mısır, mercimek, soya fasulyesi, kabuklu ceviz ve iç badem, yemeklik ayçiçeği yağı (ham), ve yemeklik mısıryağı(ham) olarak sıralanabilir. İncelenen dönemde ithalatı yapılan ürünlerin hammaddelerinin (yemeklik bitkisel yağlar hariç) dönem başından sonuna hepsinde artış gerçekleşmiştir. ithalat değerinde mutlak artış en fazla yemeklik ayçiçeği, soya fasulyesi ve buğdayda gerçekleşirken, oransal olarak en fazla artış kabuklu ceviz, iç badem, mercimek ve soya fasulyesinde elde edilmiştir.

Ayrıca bu dönemde DiR kapsamında en fazla ihracatı gerçekleştirilen işlenmiş tarım ürünleri; buğday unu, mercimek, iç ceviz, iç badem, yemeklik ayçiçeği yağı, yemeklik soya yağı ve yemeklik mısıryağıdır. İncelenen dönemde işlenmiş tarım ürünleri ihracat değerlerinde en çok artış yıllar içinde dalgalanmalara rağmen oransal olarak iç badem, iç ceviz ve yemeklik ayçiçeği yağı ve yemeklik soya yağında, mutlak olarak ise Yemeklik ayçiçeği yağı ile buğday ununda gerçekleşmiştir.

Tarımsal üretim, uygulanan tarım politikaları ve mevsimsel şartlar nedeniyle 
bazı yıllar dalgalanmalar göstermektedir. Üretimde dalgalanma tarıma dayalı sanayi için gerekli olan hammadde temininde sıkıntılara yol açarak, dışa bağlılığı artırmakta ve mevcut kapasitenin atıl duruma düşmesine neden olmaktadır. Özellikle üretim miktarının düşük olduğu ve yeterli hammadde olmamasından dolayı işletmelerin atıl kalmasının söz konusu olduğu dönemlerde hammaddenin yurt dışından temin edilerek işlenmesi ve tarımsal sanayinin rekabet gücünü kaybetmemesi amacıyla DiR sisteminin uygulanması ülke ekonomisine önemli katkı sağlayacaktır.

Tarıma dayalı sanayi işletmeleri DiR sayesinde gümrük vergilerinden muaf bir şekilde hammadde temin etmekte, girdi maliyetlerini düşürmekte, işletmelerin atıl durumda bulunan kapasitelerin çalışması sağlanmakta ve dolaylı olarak istihdam oluşturmaktadır. Bu açıdan DiR tarıma dayalı sanayi işletmeleri için çok önemli yer tutmaktadır.

Türkiye işlenmiş tarım ürünleri ihracatında DiR sayesinde hammaddenin daha kolay ve ucuz temin edilmesi ile ihraç pazarının genişletilerek ürünlerin pazarlamasında yaşanan sıkıntıların önüne geçilmektedir. Ancak DíR'in karmaşık olmasından dolayı sistemin uygulanmasında bazı aksaklıklar meydana gelmektedir. Gümrüklerde idari işlemlerin yavaş ilerlemesinden dolayı işlemlerin uzaması ve ihracat açısından yeni pazarlara girmeye çalıştıkları ülkelerde bürokratik sorunlarla karşılaşmaktadırlar.

Türkiye'de ihracatı teşvik etme ve bürokratik işlemleri yürütmede yardımcı olma konusunda yetkili olan kamu kurum ve özel sektör kuruluşları, ihracatın yarısını oluşturan DíR hakkında firmaları daha fazla bilgilendirmeli ve buna bağlı olarak yaşanan sıkıntıların aşılması için yol göstermesi ülkemiz ihracatının gelişimini sağlayacaktır.

Devlet Planlama Teşkilatı (Kalkınma Bakanlı̆ıı) tarafından hazırlanan 10. Kalkınma Planı (2014-2018) Gıda Sanayi Özel İhtisas Komisyonu Raporu'na göre, gıda ve içecek sektöründe kapasite kullanım oranının \%6070 olduğu belirtilmektedir. Raporda oranın yıllardır bu düzeyde kalmasının nedenlerinden birisinin de hammadde yetersizliği olduğundan bahsedilmektedir. Bu aşamada DiR teşvik sistemi hammadde yetersizliğini çözerek kurulu kapasitenin değerlendirilmesi açısından önemli bir ihracat teşvik sistemi olabilir.

Yapılan tüm bu değerlendirmelerden yola çıkarak Türkiye'de işlenmiş tarım ürünlerinde uygulanan DiR sisteminin dış ticareti canlandırarak ülke ekonomisine önemli katkılar sağladığı sonucu çıkarılabilir. DíR'in devam ettirilmesi atıl kapasitesini daha iyi değerlendiren işletmelere daha iyi kazanç sağlamaları için fırsat oluşturacaktır. Uluslararası piyasalarda Pazar payının artışında ve rekabet gücünü artırma konusunda avantaj sağlayacaktır.

\section{Kaynaklar}

Anonim, 2006. Dâhilde İşleme Rejimi Tebliği (ihracat 2006:12). T.C. Ekonomi Bakanlığı Ihracat Genel Müdürlüğü, Ankara.

Anonim, 2007. Dokuzuncu Kalkınma Planı (20072013) Gıda Sanayi Özel İhtisas Komisyonu Raporu. T.C. Kalkınma Bakanlığı, Ankara.

Anonim, 2011. Tarım Ürünlerine İlişkin Dahilde İşleme Rejimi Genelgesi (ihracat 2011/1), T.C. Ekonomi Bakanlığı, Ankara.

Anonim, 2012 b. Dâhilde işleme-hariçte işleme rejimi ve ìhracatçı Birlikleri'nin bu kapsamdaki görevleri. Ege ìhracatçı Birlikleri, İzmir.

Anonymous, 2012. Handbook of Best Practices at Border Crossings - A Trade and Transport Facilition Perspective. Organizaition for Security and Co-operation in Europe, United Nations. 
Anonim, 2014. http://tuikapp.tuik.gov.tr /disticaretap/menu. Erişim Tarihi: 15.02.2014.

Bıyıkçı, C., 2010. Bir teşvik rejimi olarak dahilde işleme rejiminin ülke ihracatı ve ülke kalkınması üzerindeki etkileri: gelişimsel ve ekonomi-politik bir analiz. Marmara Üniversitesi Sosyal Bilimler Enstitüsü iktisat Anadilim Dalı Yüksek Lisans Tezi.

Duru, S., 2014. Türkiye'de Bitkisel Yağ Sanayinde Dahilde İşleme Rejiminin (DiR) Uygulanabilirliği ve Etkilerinin Belirlenmesi. Mustafa Kemal Üniversitesi Fen Bilimleri Enstitüsü Gıda Mühendisliği Anabilim Dalı Yüksek Lisans Tezi.

Güneş, T., Arıkan, R., 1998. Tarım Ekonomisi İstatistiği. Ankara Üniversitesi, Ziraat Fakültesi Yayınları: 1049, Ders Kitabı: 305. Ankara

Namlı, T., 2007. Dahilde İşleme Rejimi'nin Uygulama Alanı ve Türkiye'de Etkinliği. Marmara Üniversitesi Sosyal Bilimler Enstitüsü Iktisat Anabilim Dalı Yüksek Lisans Tezi.

Yılmaz, N., 2008, Avrupa Birliği Ortak Ticaret Politikası ve Türkiye Tarımının Uyumu, T.C. Tarım ve Köyişleri Bakanlığı Dış illişkiler ve Avrupa Birliği Koordinasyon Dairesi Başkanlığı, AB Uzmanlık Tezi, Ankara. 